\title{
Games Asyik Matematika: Pengabdian Kepada Masyarakat di SD Negeri Jatirangga 3 Bekasi
}

\author{
Dyah Anungrat Herzamzam ${ }^{*}$, Evi Faujiah² \\ 1,2 STKIP Kusuma Negara, Jakarta, Indonesia \\ *Corresponding Author: dyah@stkipkusumanegara.ac.id
}

\begin{abstract}
Info Artikel
Diterima : 03/01/2021

Direvisi: 29/01/2021

Disetujui: $21 / 02 / 2021$

Abstract. Based on the analysis of the situation that occurred, the lack of socialization related to the 2013 Curriculum made many elementary school teachers including SDN Jatirangga 3 Bekasi City do not understand. Teachers of SDN Jatirangga 3 in Bekasi City have not been able to apply the 2013 Curriculum in the learning process. Based on a request letter from SDN Jatirangga 3, the Chairperson of STKIP Kus uma Negara to send PGSD lecturers to provide training to teachers there regarding the 2017 Revised 2013 Curriculum in particular. So the PGSD Study Program, STKIP Kusuma Negara sent 4 lecturers to become resource persons for the training. This training was given the theme "Having Fun with the 2013 Curriculum". With the theme "Having Fun With Curriculum 2013", it is hoped that teachers will not make the specter of the 2013 Revised Curriculum 2017 as a frightening specter. Fun Indonesian Language Games will be the main material in community service activities this time. Service activities are carried out through several stages, the following are the steps that are carried out in service: 1) Planning, the following stages Observation and searching for data about the 2013 curriculum and various fun games-based learning methods, Collaboration with schools and teachers, PKM Game development Mathematics; 2) Implementation, implementation of the 2013 Curriculum Have Fun Training; 3) Application, Application of Curriculum 2013; 4) Evaluation and Assistance, Evaluation of the strengths and weaknesses of PKM. The evaluation uses an observation sheet at the time of implementing the 2013 curriculum in the classroom. The training activities which were carried out for 2 days ran smoothly even though there were obstacles and could be overcome immediately. The selection of speakers is adjusted to the field of expertise of each lecturer with an understanding of the 2013 Curriculum. The speakers' understanding of the 2013 Curriculum enables the training participants to understand the presentation of the speakers. It is marked by the enthusiasm of the training participants during the training activities. Math Fun Game in question is a method of learning mathematics in teams. Where the training participants were divided into 2 groups.
\end{abstract}

Keywords: Fun Games, Curriculum 2013, Mathematics.

\begin{abstract}
Abstrak. Berdasarkan analisis situasi yang terjadi, Kurangnya sosialisasi terkait Kurikulum 2013 membuat guru sekolah dasar termasuk SDN Jatirangga 3 Kota Bekasi banyak yang tidak paham. Guru SDN Jatirangga 3 Kota Bekasi belum mampu mengaplikasian Kurikulum 2013 dalam proses pembelajaran. Berdasarkan surat permohonan dari SDN Jatirangga 3 kepada Ketua STKIP Kusuma Negara untuk mengirimkan dosen PGSD guna memberikan pelatihan kepada guru-guru di sana terkait Kurikulum 2013 Revisi 2017 khususnya. Maka Prodi PGSD, STKIP Kusuma Negara mengirimkan 4 dosen untuk menjadi narasumber pelatihan tersebut. Pelatihan ini diberi tema "Having Fun With Curriculum 2013". Dengan mengangkat tema "Having Fun With Curriculum 2013" diharapkan para guru tidak menjadikan momok kurikulum 2013 Revisi 2017 sebagai momok yang menakutkan. Games Asyik Matematika akan menjadi materi utama dalam kegiatan pengabdian kepada masyarakat kali ini. Kegiatan Pengabdian dilaksanakan melalui beberapa tahaan, berikut Langkah-langkah yang dilakasanakan dalam pengabdian: 1) Perencanaan, meliputi tahapan berikut Observasi dan pencarian data-data tentang kurikulum 2013 dan berbagai metode pembelajaran berbasis games asyik, Kerja sama dengan pihak sekolah dan guru, PKM Pengembangan games Matematika; 2) Pelaksanaan, dilaksanakannya Pelatihan Having Fun With Curriculum 2013; 3) Penerapan, Penerapan Kurikulum 2013; 4) Evaluasi dan Pendampingan, Evaluasi terhadap kelebihan dan kelemahan PKM. Evalusai menggunakan lembar observasi pada saat penerpaan kurikulum 2013 di kelas. Kegiatan pelatihan yang dilaksanakan selama 2 hari ini berlangsung dengan lancar walau ada hambatan dan dapat segera diatasi. Pemilihan pemateri disesuiakan dengan bidang keahlian masing-masing dosen dengan pemahaman terhadap Kurikulum 2013. Pemahaman pemateri terhadap Kurikulum 2013 membuat peserta pelatihan mampu memahami pemaparan dari pemateri. Ditandai dengan antusiasnya peserta pelatihan selama kegaiatan pelatihan. Games Asyik Matematika yang dimaksud adalah metode pembelajaran matematika secara beregu. Dimana peserta pelatihan dibagi menjadi 2 kelompok
\end{abstract}

Kata Kunci: Games Asyik, Kurikulum 2013, Matematika.

How to Cite: Herzamzam, D. A., \& Faujiah, E. (2021). Games Asyik Matematika: Pengabdian Kepada Masyarakat di SD Negeri Jatirangga 3 Bekasi. Prima Abdika : Jurnal Pengabdian Masyarakat, 1(1), 1-6. (2021). https://doi.org/10.37478/abdika.v1i1.916 


\section{Pendahuluan}

Pentingnya pendidikan bukan suatu hal yang diragukan lagi di seluruh dunia khususnya di Indonesia. Melalui pendidikan orang-orang lebih dapat mengoptimalkan bakat dan kemampuan yang mereka miliki. Mutu pendidikan akan mempengaruhi bagus atau tidakanya hasil yang diperoleh dari suatu proses pendidikan. Mutu pendidikan merupakan masalah yang dijadikan agenda utama untuk diatasi dalam kebijakan pembangunan pendidikan, karena hanya dengan pendidikan yang bermutu akan diperoleh lulusan bermutu yang mampu membangun diri, keluarga, masyarakat bangsa dan negara. Salah satu kompetensi yang harus dikuasai siswa dalam proses pendidikan adalah kompetensi matematika. Lulusan tingkat sekolah dasar yang bermutu seharusnya memiliki kompetensi matematika yang baik terutama literasi matematika yang berguna bagi dirinya untuk mengarungi hidup maupun dalam belajar matematika di tingkat sekolah yang lebih tinggi.

Menurut Novitasari (2016), matematika sebagai salah satu bidang studi yang diajarkan di lembaga pendidikan formal merupakan salah satu bagian penting dalam upaya meningkatkan mutu pendidikan. Pelajaran matematika adalah suatu pelajaran yang berhubungan dengan banyak konsep, agar konsep-konsep dapat dipahami secara utuh maka guru diharpkan mengemas menjadi pembelajaran yang menyenangkan.

Untuk mencapai tujuan seperti yang diuraikan di atas, juga perlu guruguru yang memiliki kompetensi yang baik. Oleh karena itu guru-guru perlu diberikan penyegaran-penyegaran agar kompetensinya dapat meningkat melalui pengalaman-pengalaman baru sesuai tuntutan pedagogi matematika dalam Kurikulum 2013. Trend penelitian pembelajaran matematika sekarang ini berorientasi pada cara-cara yang dapat membuat siswa belajar matematika bermakna dan menyenangkan. Beberapa rekomendasi penelitian-penelitian tersebut adalah pembelajaran matematika kontekstual berbasis permainan (games) yang dikenal oleh anak-anak. Aktivitas bermain anak merupakan konteks yang baik bagi pembelajaran matematika yang bermakna dan menyenangkan menggunakan pendekatan pendidikan matematika realistik dengan syarat bahwa permainan-permainan tersebut mengandung fenomena matematis tertentu (Bito, 2014).

Selain pembelajaran matematika berbasis permainan, Kurikulum 2013 juga menekankan pembelajaran berbasis budaya termasuk pembelajaran matematika. Pembelajaran matematika berbasis budaya dapat dilaksanakan dengan etnomatematika termasuk etnomatematika pada permainanpermainan anak yang ditemukan pada budaya. Mulyasa (2014) dalam bukunya berpendapat Kurikulum 2013 dibuat seiring dengan kemerosotan karakter bangsa Indonesia pada akhir-akhir ini. Korupsi, penyalahgunaan obat terlarang, pembunuhan, kekerasan, premanisme, dan lain-lain adalah kejadian yang menunjukkan kualitas pendidikan dan sumber daya manusia yang rendah serta rapuhnya fondasi moral dan spiritual kehidupan bangsa. Selain itu, penyebab perlunya mengembangkan kurikulum 2013 adalah beberapa hasil dari riset internasional yang dilakukan oleh Global Institute dan Programme for International Student Assessment (PISA) merujuk pada suatu simpulan bahwa prestasi peserta didik Indonesia tertinggal dan 
terbelakang, khususnya pada mata pelajaran matematika, yang sering dianggap sulit oleh siswa-dan siswi. Dengan demikian, pembelajaran matematika memiliki tujuan selain untuk penguasaan konsep matematika juga mendidik karakter peserta didik. Etnomathematika dapat diintegrasikan ke dalam pembelajaran matematika di sekolah dasar dalam mendidik karakter peserta didik seperti sikap tanggung jawab, suka bekerja keras, mengamalkan nilai-nilai agama, mengembangkan kreativitas, persahabatan, tanggung jawab, semangat kerjasama dan kekeluargaan serta toleransi (Fredy et al., 2020).

Berdasarkan analisis situasi yang terjadi, kurangnya sosialisasi terkait Kurikulum 2013 membuat guru sekolah dasar termasuk SDN Jatirangga 3 Kota Bekasi banyak yang tidak paham. Guru SDN Jatirangga 3 Kota Bekasi belum mampu mengaplikasian Kurikulum 2013 dalam proses pembelajaran. Berdasarkan surat permohonan dari SDN Jatirangga 3 kepada Ketua STKIP Kusuma Negara untuk mengirimkan dosen PGSD guna memberikan pelatihan kepada guru-guru di sana terkait Kurikulum 2013 Revisi 2017 khususnya. Maka Prodi PGSD, STKIP Kusuma Negara mengirimkan 4 dosen untuk menjadi narasumber pelatihan tersebut. Pelatihan ini diberi tema "Having Fun With Curriculum 2013". Dengan mengangkat tema "Having Fun With Curriculum 2013" diharapkan para guru tidak menjadikan momok kurikulum 2013 Revisi 2017 sebagai momok yang menakutkan. Games Asyik Matematika akan menjadi materi utama dalam kegiatan pengabdian kepada masyarakat kali ini dengan menggunakan game-game tradisional dari masyarakat Jawa Tengah. Berbagai strategi yang efisein dan efektif dapat diterapkan dalam pembelajaran seperti Games asik matematika diantaranya:

1) Pathilan

Pathilan adalah permainan tradisional dari pulau Jawa khususnya Jawa tengah (De Araujo et al., 2014). Permainan ini menggunakan lidi sebagai alat untuk memainkannya. Fungsinya untuk membelajarkan anak mengenai penjumlahan.

2) Dakon

Dakon adalah salah satu jenis permainan daerah dari Yogyakarta. Tempat untuk memainkan dakon bisa menggunakan tanah yang telah dibuat lubang dengan ukuran tertentu.

3) Nekeran

Nakeran adalah jenis permainan yang sangat familiar untuk anak-anak di seluruh daerah di Indonesia dapat diaplikasikan dalam materi kertas operasi hitung matematika. 
4) Kubuk manuk

Kubuk Manuk adalah jenis permainan dari Yogyakarta yang dapat diaplikasikan pada materi operasi hitung misalnya penjumlahan, pengurangan, perkalian, dan pembagian.

\section{Metode Pelaksanaan}

Kegiatan Pengabdian dilaksanakan melalui beberapa tahaan, berikut Langkah-langkah yang dilakasanakan dalam pengabdian: 1) Perencanaan, meliputi tahapan berikut Observasi dan pencarian data-data tentang kurikulum 2013 dan berbagai metode pembelajaran berbasis games asyik, Kerja sama dengan pihak sekolah dan guru, PKM Pengembangan games Matematika; 2) Pelaksanaan, dilaksanakannya Pelatihan Having Fun With Curriculum 2013; 3) Penerapan, Penerapan Kurikulum 2013; 4) Evaluasi dan Pendampingan, Evaluasi terhadap kelebihan dan kelemahan PKM. Evalusai menggunakan lembar observasi pada saat penerpaan kurikulum 2013 di kelas.

\section{Hasil dan Pembahasan}

Kegiatan pelatihan yang dilaksanakan selama 2 hari ini berlangsung dengan lancar walau ada hambatan dan dapat segera diatasi. Pemilihan pemateri disesuiakan dengan bidang keahlian masing-masing dosen dengan pemahaman terhadap Kurikulum 2013. Pemahaman pemateri terhadap Kurikulum 2013 membuat peserta pelatihan mampu memahami pemaparan dari pemateri. Ditandai dengan antusiasnya peserta pelatihan selama kegaiatan pelatihan. Games Asyik Matematika yang dimaksud adalah metode pembelajaran matematika secara beregu.

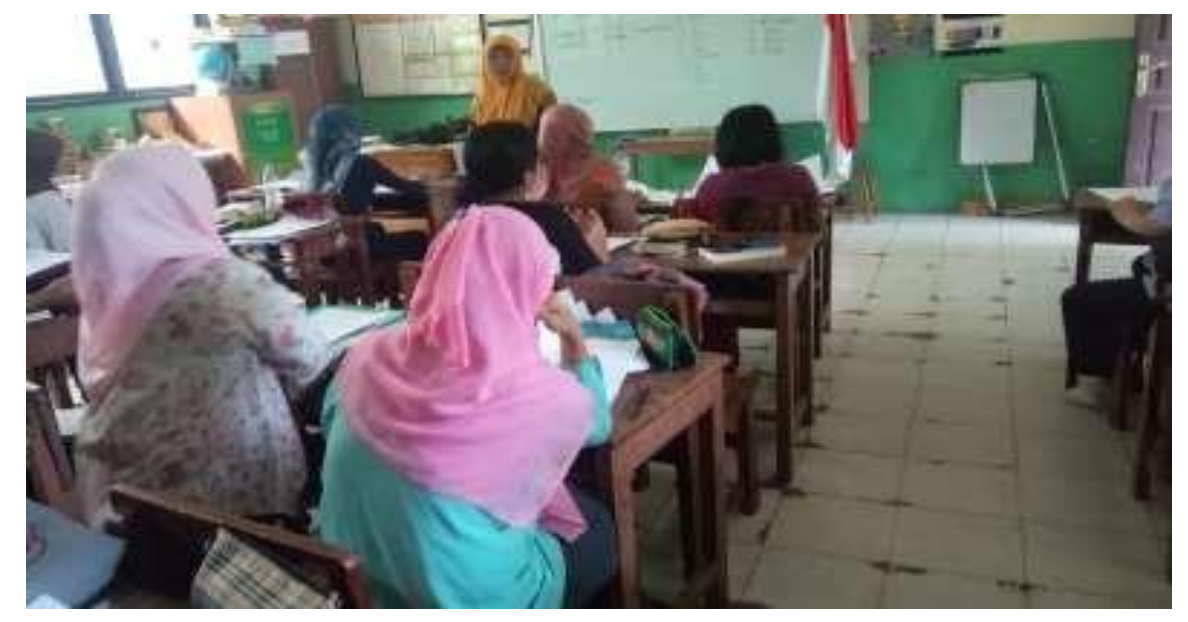

Gambar 1. Pemateri Memaparkan Materi PKM 


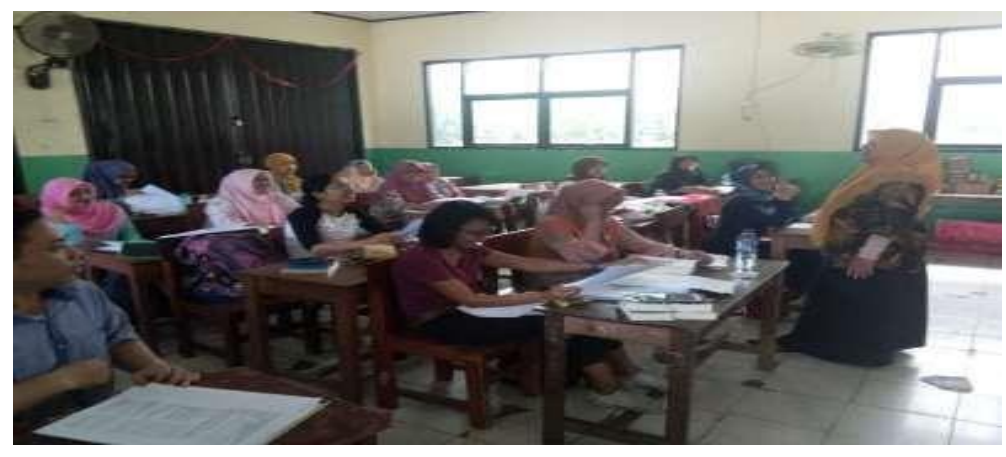

Gambar 2. Tim PKM Berdiskusi

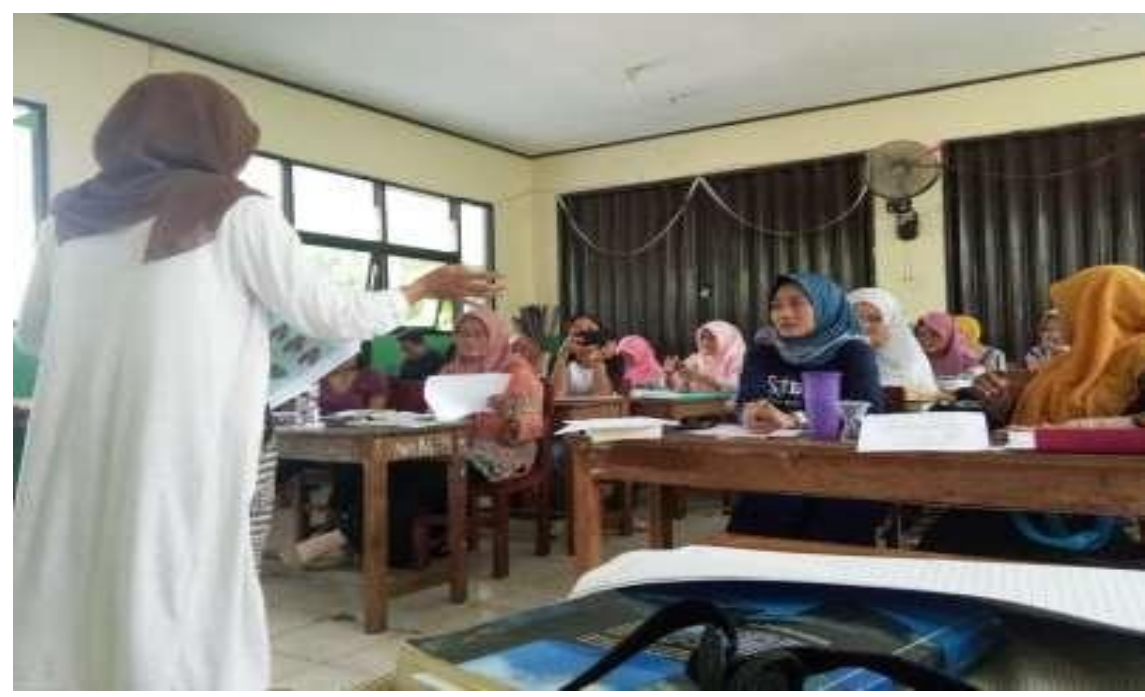

Gambar 3. Peserta PKM Menyimak Meteri yang disampaikan

Dimana peserta pelatihan dibagi menjadi 2 kelompok. Kegiatan ini berlangsung secara atraktif dan membuat para peserta bersemangat dan diakhiri dengan pemberian reward kepada kelompok yang memenangkan games. Peserta PKM terdiri dari seluruh guru di SD Negeri Jatirangga 3, yaitu berjumlah 30 guru. Namun dari peserta yang ditargetkan terdapat beberapa guru yang tidak dapat hadir yaitu hanya 25 guru yang dapat hadir. Berikut penjelasan singkat mengenai hasil dari evalusai yang telah dilaksanakan.

Table 1. Hasil Evalusai Pelaksanaan Pengabdian

\begin{tabular}{llcc}
\hline & & Jumlah & $\%$ \\
\hline & $\begin{array}{l}\text { Ketercapaian target jumlah } \\
\text { pesertapelatihan }\end{array}$ & 25 & 69,4 \\
\cline { 2 - 3 } $\begin{array}{l}\text { Komponen } \\
\text { Keberhasilan PKM }\end{array}$ & 15 & 60 \\
\cline { 2 - 3 } & $\begin{array}{l}\text { Ketercapaian tujuan pelatihan } \\
\text { telah direncanakan }\end{array}$ & 20 & 80 \\
\hline & $\begin{array}{l}\text { Kemampuan peserta dalam } \\
\text { penguasaan materi }\end{array}$ & 20 & 80 \\
\hline
\end{tabular}




\section{Simpulan dan Tindak Lanjut}

Adapun kesimpulan dari pelaksanaan pengabdian kepada masyarakat di SD Negeri Jatirangga 3 Bekasi adalah sebagai berikut: 1) Kegiatan pelatihan diberikan tema Having Fun with Curriculum 2013: Games Asyik Matematika. 2) Kegiatan dilakukan selama 2 hari; 3) Kegiatan pelatihan juga diberikan ice breaking untuk memecah kebosanan peserta. Kegiatan pengabdian seperti ini dapat dilakukan secara rutin baik di lokasi yang sama maupun di lokasi yang berbeda dengan sasaran para guru yang memang masih awam terkait Kurikulum 2013

\section{Daftar Pustaka}

Bito, G. S. (2016). Aktivitas bermain sebagai konteks dalam belaiar matematika di sekolah dasar dengan pendekatan matematika realistik. Jurnal Pemikiran dan Pengembanqan Sekolah Dasar (JP2SD), 1(4), 250-255. https:// doi.org/10.22219/ip2sd.v1i4.2796

Fredy, F., Tembang, Y., Bito, G. S., \& Sholikhah, O. H. (2020). Exploration Ethnomathematics of the Malind Tribe for Character Building in Elementary Schools. International Journal on Advanced Science, Education, and Religion, 3(2), 9-20. https: / / doi.org/ 10.33648/ijoaser.v3i2.58

Novitasari, D. (2016). Pengaruh penggunaan multimedia interaktif terhadap kemampuan pemahaman konsep matematis siswa. FIBONACCI: Jurnal Pendidikan Matematika Dan Matematika, 2(2), 8-18. https:/ / doi.org/ 10.24853/fbc.2.2.8-18

Mulyasa, E.(2014). Pengembangan dan Implementasi Kurikulum 2013. Bandung: Remaja Rosdakarya. Google Scholar

Peraturan Pemerintah Republik Indonesia Nomor 19 tahun 2005 tentang Standar Nasional Pendidikan.

De Araujo, D., Kusumastuti, B., Widyaningrum, S. N., Sidharta, A. P., \& Hardiyanti, B. T. (2014, January). Peningkatan Kemampuan Belajar Hitung pada Anak melalui Ragam Permainan Kreatif. In Pekan Ilmiah Mahasiswa Nasional Program Kreativitas Mahasiswa-Penaabdian Kepada Masyarakat 2013. Indonesian Ministry of Research, Technology and Higher Education. 